IBIMA Publishing

Journal of Research and Practice in Dentistry

http://www.ibimapublishing.com/journals/DENT/dent.html

Vol. 2014 (2014), Article ID 452422, 11 Pages

DOI: $10.5171 / 2014.452422$

Research Article

\title{
Skeletal Facial Morphology and Third Molar Agenesis
}

\author{
Nurgül Kömerik ${ }^{1}$, Olgun Topal ${ }^{2}$, Elçin Esenlik ${ }^{3}$ and Esra Bolat ${ }^{4}$ \\ ${ }^{1,2}$ Dept of Oral and Maxillofacial Surgery, Suleyman Demirel University, Dental Faculty, Isparta, Turkey \\ ${ }^{3,4}$ Dept of Orthodontics, Suleyman Demirel University, Dental Faculty, Isparta, Turkey
}

Correspondence should be addressed to: Nurgul Komerik; nurgulkomerik@gmail.com

Received date: 26 September 2013; Accepted date: 25 November 2013; Published date: 22 August 2014

Academic Editor: Anmol S. Kalha

Copyright (C 2014. Nurgül Kömerik, Olgun Topal, Elçin Esenlik and Esra Bolat. Distributed under Creative Commons CC-BY 3.0

\begin{abstract}
Aim: The aim of this study was to examine whether there is a relationship between third molar agenesis, and skeletal jaw morphology in sagittal and vertical planes. Materials and Methods: Records of 108 orthodontic patients were evaluated. Skeletal jaw variables (SNA, SNB and ANB angles, lower anterior to total facial height ratio, mandibular plane angle, maxillary plane angle, maxillo-mandibular plane angle) were determined using lateral cephalograms. The frequency of maxillary and mandibular third molar agenesis was evaluated in different face types. Results: Agenesis of third molars was more frequent in patients with smaller jaw morphology in sagittal plane $(21.1 \%$ in the mandible and $36.8 \%$ in the maxilla). In addition, patients with short face and deep bite had higher frequency of third molar agenesis both in the mandible and the maxilla. While, those who had hypodivergent pattern had higher rate of third molar agenesis in the mandible (27.3\%), those with an anteriorly rotated maxilla had higher rate of third molar agenesis in the maxilla (35.3\%). Conclusion: Third molar agenesis, in both jaws, appears to be related to the jaw relations in sagittal and vertical plane.
\end{abstract}

Keywords: Third molar agenesis, cephalometrics, sagittal, vertical, maxilla, mandible

\section{Introduction}

When compared to the rest of the dentition, third molars stand out having distinctive characteristics and behavior. They are the most commonly impacted teeth, associated with a host of pathologies and are therefore, the most commonly extracted teeth. In addition, third molars are the most frequent teeth to show agenesis $(1,2)$. A comprehensive study that screened 100,577 populations in Turkey showed that, excluding third molars, the prevalence of hypodontia was $3.1 \%$ and the prevalence of oligodontia was $0.07 \%$ (3). Topkara and Sari (2011) reported that the prevalence of congenitally missing teeth in the overall orthodontic population was $30.6 \%$ which dropped to $6.8 \%$ when third molar agenesis was excluded in the study population (2). In another study, $24 \%$ among 2,579 subjects were diagnosed with third-molar agenesis of whom $9 \%$ had 1 , $8 \%, 2,3 \%, 3$, and $4 \%$ had all third-molars

Cite this Article as: Nurgül Kömerik, Olgun Topal, Elçin Esenlik and Esra Bolat (2014), "Skeletal Facial Morphology and Third Molar Agenesis", Journal of Research and Practice in Dentistry, Vol. 2014(2014), 
missing (4). Kajii et al (2001) reported that existence of all 4 third molar germs is approximately $77 \%$ in Japanese orthodontic patients (5). Agenesis, in general dentition 1 and in third molars was more common in the maxilla than in the mandible (5-7).

Since the growth and development of the alveolar processes is guided by the formation and eruption of the tooth, agenesis of the permanent teeth would be expected to be associated with smaller jaw size. Celikoglu et al (2010) reported that intercanine and intermolar widths in the maxillary and mandibular arches were significantly reduced in the patients with hypodontia (8). Although, maxillary hypodontia was generally associated with decreased maxillary jaw size (9), tooth agenesis had relatively little effect on mandibular size (1). Woodworth et al (1985) reported that patients exhibiting bilateral congenital absence of maxillary lateral incisors had retrognatic maxilla (10). They also pointed out that these patient populations had a tendency of having shorter lower, upper facial height and forward mandibular rotation. Endo et al (2012) reported that all the patients with hypodontia exhibited shorter anterior and overall cranial base lengths, and shorter maxillary length (11). Hypodontia of the anterior teeth exerted as much influence on craniofacial morphology as hypodontia of the posterior segment.

Nevertheless, hypodontia on both anterior and posterior dentition had more pronounced effects compared to hypodontia, either on the anterior dentition or on the posterior dentition. However, they failed to show any difference in vertical dimension measurements between hypodontia group and the control group (1). Other authors conclude that dental agenesis exerts little influence on dentofacial structures $(12,13)$. Øgaard and Krogstad (1995) concluded that the typical dentofacial appearance in advanced hypodontia may be due to dental and functional compensations rather than to skeletal growth retardation (12).

Only a handful of studies have evaluated the relationship between third molar agenesis and craniofacial morphology $(5,6$, and 14). The majority of these reports mainly focused on the third molar agenesis and the sagittal skeletal jaw relationships. Therefore, the aim of this study was to delineate whether the jaw morphology in both sagittal and vertical planes is related to third molar agenesis in the maxilla and mandible independently.

\section{Materials and Methods}

Records of patients over the age of 15 who were treated by the orthodontist (third author) between 2008-2012 were collected. The exclusion criteria were patients younger than 15 years old; patients with developmental anomalies such as ectodermal dysplasia, cleft lip or plate; patients with an asymmetric deformity on the face; patients with a missing tooth other than third molars; patients who had undergone previous orthodontic treatment, dentoalveolar surgery or patients who had maxillofacial trauma and radiographs of poor quality. A total of 108 patients were enrolled in the study. Demographic data as the age and gender of the patients were recorded. Lateral skull and panoramic radiographies taken at the initial examination were evaluated.

The project was approved by the Clinical Studies Ethics Committee at the Suleyman Demirel University, and written informed consent was obtained from participants

(Registration no: 30.2.SDÜ.0.20.05.00-0503265).

\section{Assessment of the Third Molars}

Radiographic examinations on orthopantomographs were performed to determine the presence of third molar germs. Supported by negative history of previous extraction, and no evidence of previous extraction on patient's records, a tooth was classified as congenitally missing when no sign of mineralization of the crown could be identified on radiographs. 


\section{Assessment of Craniofacial Morphology}

Craniofacial morphology in relation to sagittal and vertical planes was determined using lateral skull graphies which were taken using the same cephalostat and with the standardized settings.
For cephalometric analysis, reference lines were manually drawn on transparent acetate film and reference points were defined. Linear and angular measurements related to the jaw geometry were identified. The white Caucasian standard values were used to set normal norms (15). The parameters related to the skeletal jaw relationships were listed in Table 1.

\begin{tabular}{|c|c|c|c|}
\hline Measurements & $\begin{array}{l}\text { Caucasian } \\
\text { norm }\end{array}$ & Interpretation & $\begin{array}{l}\text { Number } \\
\text { of } \\
\text { individual } \\
\mathrm{s}\end{array}$ \\
\hline \multirow[t]{3}{*}{ ANB } & \multirow[t]{3}{*}{$3^{\circ}( \pm 2)$} & Skeletal class I & 43 \\
\hline & & $>$ Skeletal class II & 38 \\
\hline & & < Skeletal class III & 27 \\
\hline \multirow[t]{3}{*}{ SNA } & \multirow[t]{3}{*}{$81^{\circ}( \pm 3)$} & Orthognatic maxilla & 58 \\
\hline & & $<$ Retrognatic maxilla & 38 \\
\hline & & $>$ Prognatic maxilla & 12 \\
\hline \multirow[t]{3}{*}{ SNB } & \multirow[t]{3}{*}{$78^{\circ}( \pm 3)$} & Orthognatic mandible & 49 \\
\hline & & $<$ Retrognatic mandible & 33 \\
\hline & & $>$ Prognatic mandible & 26 \\
\hline Lower anterior face & \multirow[t]{3}{*}{$55 \%( \pm 2)$} & Normal facial proportion & 55 \\
\hline height ratio (ANS- & & $<$ Short face & 15 \\
\hline $\mathrm{Me} / \mathrm{N}-\mathrm{Me})$ & & $>$ Long face & 38 \\
\hline \multirow[t]{3}{*}{$\begin{array}{l}\text { Mandibular Plane Angle } \\
\text { (SN:GoGn) }\end{array}$} & \multirow[t]{3}{*}{$32^{\circ}( \pm 3)$} & $\begin{array}{l}\text { Normally inclined } \\
\text { mandible }\end{array}$ & 42 \\
\hline & & $<$ Hipodivergant & 22 \\
\hline & & >Hiperdivergant & 44 \\
\hline \multirow{3}{*}{$\begin{array}{l}\text { Maxillary Plane Angle } \\
\text { (SN:ANS-PNS) }\end{array}$} & \multirow{3}{*}{$8^{\circ}( \pm 3)$} & Normally inclined maxilla & 64 \\
\hline & & $\begin{array}{l}\text { Counter clock-wise } \\
\text { rotation }\end{array}$ & 10 \\
\hline & & Clock-wise rotation & 34 \\
\hline Mandibular & \multirow[t]{3}{*}{$27^{\circ}( \pm 4)$} & Normal vertical relation & 49 \\
\hline Plane Angle (ANS- & & $<$ skeletal deep-bite & 45 \\
\hline PNS:GoGn) & & $>$ Skeletal open-bite & 13 \\
\hline
\end{tabular}

\section{Sagittal Skeletal Relationships}

The amount of skeletal discrepancy between maxilla and mandible was calculated by ANB angle of which $3^{\circ}( \pm 2)$ regarded as normal range. Accordingly, skeletal relationship was established as
Class I (ANB of $1-5^{\circ}$ ), Class II (ANB of more than $5^{\circ}$ ) and Class III (ANB of less than $1^{\circ}$ ). Relative position of the maxilla to the cranial base $\left(\mathrm{SNA}^{\circ}\right)$ was measured. SNA angle of $81^{\circ}( \pm 3)$ was regarded as standard. A value above the normal range was regarded as prognathic maxilla, and 
below the normal range was regarded as retrognathic maxilla.

Relative position of the mandible to the cranial base $\left(\mathrm{SNB}^{\circ}\right)$ was also measured and SNB angle of $78^{\circ}( \pm 3)$ was regarded standard. A value above this range was interpreted as mandibular prognathism, and a value below as mandibular retrusion.

\section{Vertical Skeletal Relationships}

Vertical facial proportions were calculated by the ratio of the lower anterior facial height (distance between ANS to Me) to total anterior facial height (distance between $\mathrm{N}$ to $\mathrm{Me}$ ). It is calculated as a percentage by the equation of (lower facial height/total facial height) $\times 100$. A ratio of $55 \%( \pm 2)$ was regarded as a normal index. Values greater than the normal range indicate increased lower facial height (long face), smaller values indicate decreased facial height (short face).

Vertical inclination of the mandible to the cranial base was measured by mandibular plane angle (SN to GoMe). The mean value was regarded as $32^{\circ}( \pm 3)$. Values greater than the normal indicate posterior rotation of the mandible (hyperdivergent pattern) whereas, smaller values indicate anterior rotation of the mandible (hypodivergent pattern).

Vertical inclination of the maxilla to the cranial base was measured by maxillary plane angle (SN to ANS-PNS). Values greater than the normal indicate posterior rotation of maxilla (clock-wise rotation) whereas, smaller values indicate anterior rotation of maxilla (counter clock-wise rotation).

Maxillo-mandibular angle was measured by maxillary-mandibular plane angle (ANSPNS to GoMe). The mean value is $27( \pm 4)$. Higher values represent skeletal openbite, lower values represent skeletal deep-bite.

\section{Assessment of the Arch Lengths}

Maxillary arch length was measured as the distance from point $A$ to the intersection of pterygoid fossa and maxillary plane, whereas mandibular arch length was measured as the distance from point $B$ to the intersection of anterior border of ramus with the body of the mandible.

\section{Analysis of the Data}

To determine the errors associated with the measurements, $10 \%$ of the lateral cephalograms and panoramic radiographs were selected randomly, and re-evaluated repeating all the measurements 3 weeks after the first evaluation by the same investigator. The reproducibility of $100 \%$ was obtained in the identification of agenesis. The intra-examiner reproducibility was $98 \%$ for the skeletal relationships. Frequencies and percentages were given as a descriptive statistics. The Pearson chi-square test was performed to assess whether third molar agenesis is independent of each skeletal jaw morphology determined by cephalometric measurements. Mann Whitney U test was applied to compare the differences in arch length in agenesis and non-agenesis groups. Pearson correlation was used to determine any correlation between arch length, and cephalometric measurements in sagittal plane.

\section{Results}

A total of 108 individuals, comprising 65 females and 43 males, had a mean age of $17.11( \pm 2.38$ ) years. Female and male participants had similar age group (16.39, \pm 1.50 years old and $17.59 \pm 2.72$ years old, respectively).

Of the 108 patients, $40(37 \%)$ had agenesis of 1 or more third molar. Most of the patient with agenesis had either 1 or 2 third molar missing $(11.1 \%$ and $16.1 \%$ respectively). The ratio of patients with 3 third molar missing, and all the third molars missing were $5.6 \%$.

Table 2 shows the distribution of third molar agenesis in the mandible and maxilla. Of the total individuals with agenesis, $84 \quad(77.8 \%)$ had bilaterally formed third molars in the mandible, and $80(74.1 \%)$ had bilaterally formed third molars in the maxilla. Bilateral agenesis was more common than unilateral agenesis both in the maxilla and the mandible 
Table 2: The frequency and percentage of patients according to agenesis characteristics of third molars

\begin{tabular}{lccccl}
\hline & Right side & Left side & $\begin{array}{l}\text { Unilateral } \\
\text { or bilateral }\end{array}$ & Unilateral & Bilateral \\
\hline Mandibular & $17(15.5 \%)$ & $21(19.4 \%)$ & $24(22.2 \%)$ & $10(9.3 \%)$ & $14(13 \%)$ \\
Maxillary & $24(22.2 \%)$ & $24(22.2 \%)$ & $28(25.9 \%)$ & $8(7.4 \%)$ & $20(18.5 \%)$ \\
& & & & & \\
\hline
\end{tabular}

\section{Agenesis in Relation to Jaw Morphologies in Sagittal Plane}

Of the individuals with skeletal Class III jaw relations, $7.9 \%$ had third molar agenesis in the mandible and $29.6 \%$ in the maxilla. Third molar agenesis was $25.9 \%$ in the mandible, and $13.2 \%$ in the maxilla of patients with skeletal Class II jaw relation (Figure 1a).

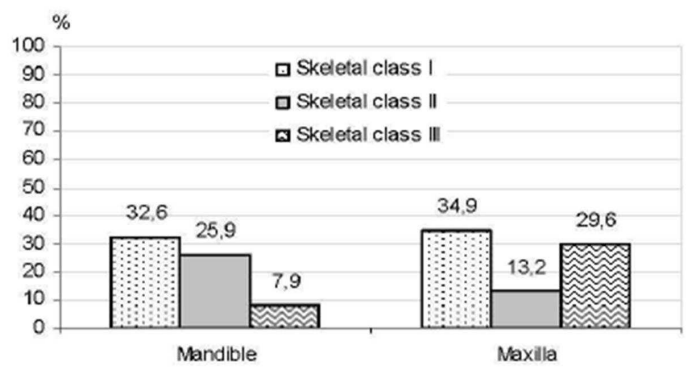

Figure 1a: Percentage of third molar agenesis in various forms of jaw relationship in sagittal plane

Mandibular third molar agenesis was lower $(7.7 \%)$ in individuals with mandibular prognathism, and higher $(21.1 \%)$ in those with mandibular retrognathism. Similarly, maxillary third molar agenesis was lower
(16.7\%) in individuals with maxillary prognathism and higher $(36.8 \%)$ in those with maxillary retrognathism (Figure $1 \mathrm{~b}$ and 1c) 


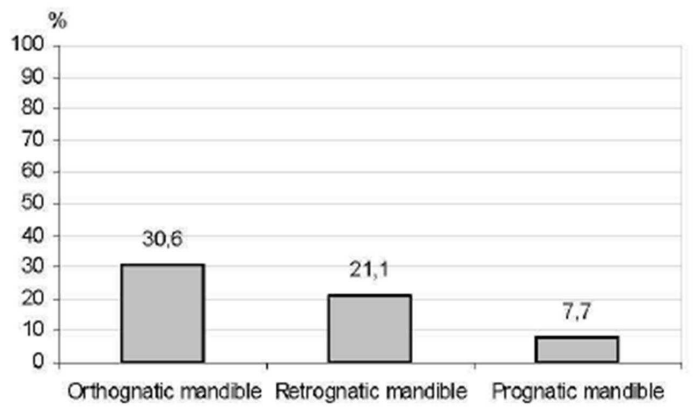

Figure 1b: Percentage of mandibular third molar agenesis in various forms of mandible in relation to cranium in sagittal plane

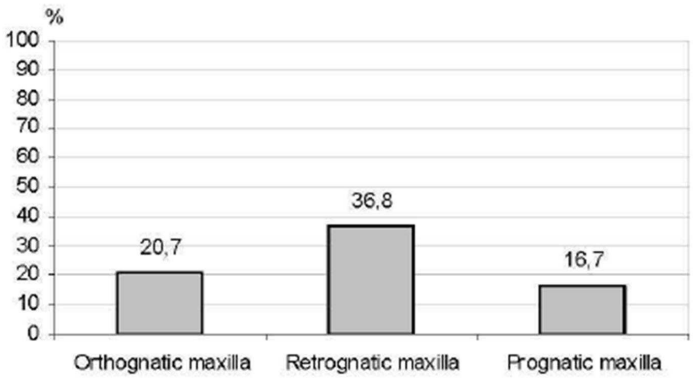

Figure 1c: Percentage of maxillary third molar agenesis in various forms of maxilla in relation to cranium in sagittal plane

Among all sagittal skeletal jaw relations, only mandibular third molar agenesis and skeletal jaw relations in sagittal plane were not independent of each other $(\mathrm{p}=0.025)$.

\section{Agenesis in Relation to Jaw Morphologies in Vertical Plane}

Individuals with short face and with deep bite had higher frequency of third molar agenesis, both in the mandible and maxilla (Figure 2 and Figure 3a, 3b and 3c). While, those who had hypodivergent mandible had higher rate of third molar agenesis in the mandible (27.3\%), those with anteriorly rotated maxilla had higher rate of third molar agenesis in the maxilla (35.3\%). 
Among all vertical skeletal jaw relations, only maxillary third molar agenesis and lower face height ratio were found to be not independent of each other

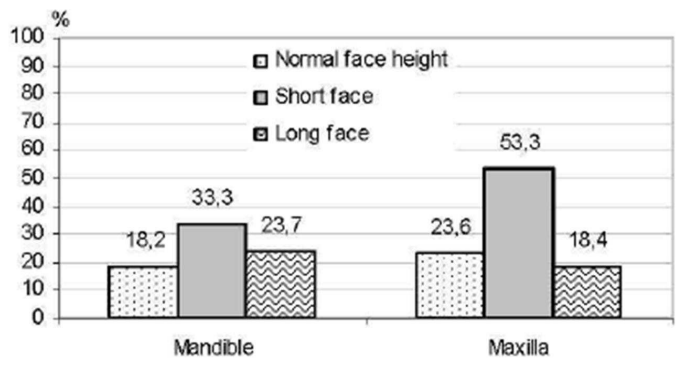

Figure 2: Percentage of third molar agenesis with regard to various lower face height ratio

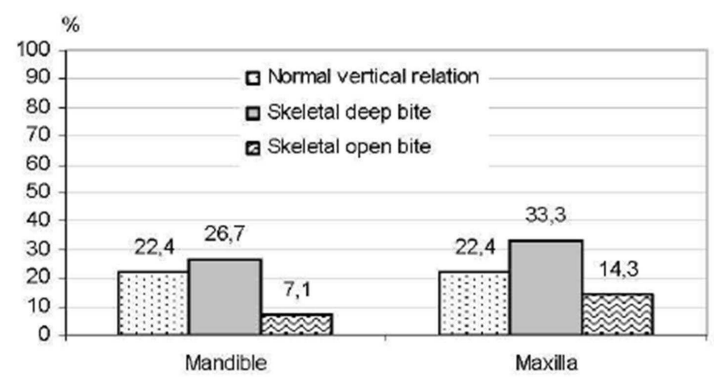

Figure 3a: Percentage of third molar agenesis in relation to various forms of maxillo-mandibular plane angles 


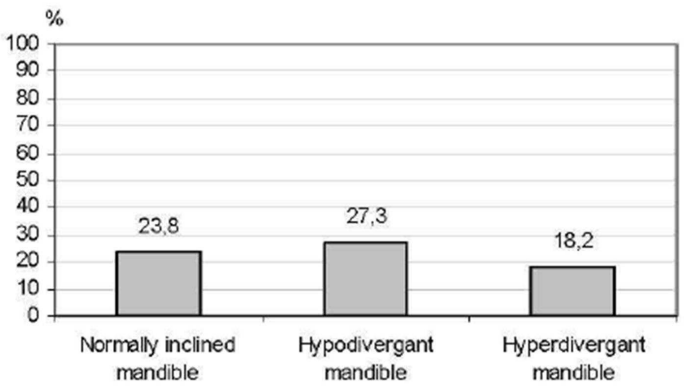

Figure 3b: Percentage of mandiblular third molar agenesis in various forms of mandibular plane angles in relation to cranium.

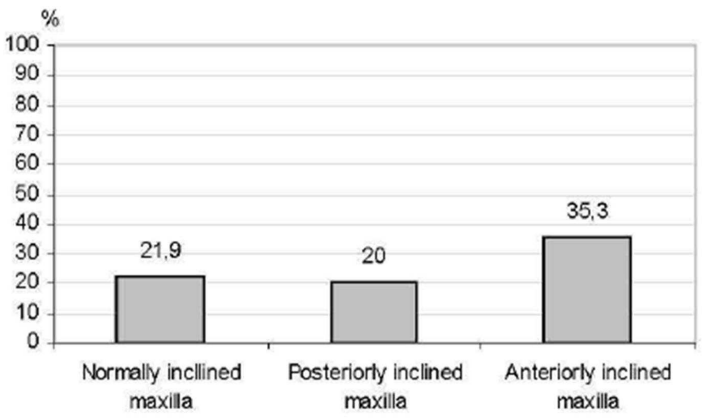

Figure 3c: Percentage of maxillary third molar agenesis in various forms of maxillary plane angles in relation to cranium.

\section{Agenesis in Relation to Arch Length}

The mean maxillary arch length was 49.4 $( \pm 3.4) \mathrm{mm}$ in the subjects with unilateral or bilateral third molar agenesis compared to $50.8( \pm 3.9) \mathrm{mm}$ in subjects having both third molars. The mean arch length in the mandible was $48.6( \pm 3.7) \mathrm{mm}$ in the agenesis group as opposed to $50.6( \pm 5.1)$ $\mathrm{mm}$ non-agenesis group. However, the differences were not statistically significant.

Maxillary arch length was correlated with SNA ( $p=0.000)$ and ANB $(p=0.012)$ and mandibular arch length was correlated with SNB $(p=0.000)$ and ANB $(p=0.000)$. 


\section{Agenesis in Relation to Effective Maxillary and Mandibular Lengths}

The mean maxillary effective length was $87.8( \pm 4.4)$ in the subjects with maxillary third molar agenesis (either unilateral or bilateral) compared to $89.71( \pm 5,5)$ in the non-agenesis group.

The mean mandibular effective length was $115.71( \pm 5.0)$ in the subjects with mandibular third molar agenesis, while $121( \pm 3,08)$ in the non-agenesis group.

Although, the difference was not statistically significant, those with agenesis had shorter effective length in both maxilla and mandible.

\section{Discussion}

The presence of the third molars may influence orthodontic treatment planning and the overall treatment stability. The relationship between third molars and crowding, especially seen after orthodontic treatment has been still controversial. Thus, genesis/agenesis together with the calcification and eruption times of these teeth is of a great importance. Therefore, the presence of third molars in various jaws morphology was investigated in this study.

Some studies have shown that hypodontia was associated with sagittal craniofacial discrepancies $(1,9-11,16)$. Hypodontia, in general, tends to occur more commonly in patients who have Class III malocclusion5. Third molar hypodontia seems to follow a similar pattern. It was shown that third molar agenesis was seen less in patients with skeletal Class II, and was most common in Class III skeletal relationship $(6,16)$. Celikoglu and Kamak (2012) reported that the prevalence of third molar agenesis in those with a Class III malocclusion $(28.4 \%)$ was significantly higher than in those with Class I (20.3\%), and Class II (19.9\%) malocclusion (6).

Similarly, Kajii et al (2001) reported that percentage of skeletal Class III subjects who had all 4 third molars was lower than those of skeletal Class I and Class II subjects (5). While of the subjects with skeletal Class III jaw relationship 29\% had 1 or more third molar agenesis, $19.3 \%$ of the skeletal Class II subjects, and $21.8 \%$ of the skeletal Class I subjects had agenesis of the third molars. In the present study, it is further investigated whether a similar trend of the jaw relations in the sagittal plane was applicable when the third molar agenesis is determined in the maxilla and mandible independently. We found that maxillary third molars were more frequently found to be missing in the subjects with Class III jaw relations whereas mandibular third molars were more frequently absent in the subjects with Class II jaw relations. Furthermore, when the discrepancy of the jaw relationship was analyzed in detail according to jaw sizes in relation to cranium, our results contributes to the literature for the first time that mandibular third molar agenesis was less frequent in subjects with mandibular prognathia, and maxillary third molar agenesis was less frequent in subjects with maxillary prognathia. We believe that the findings, although statistically not significant, are clinically relevant.

Vertical skeletal characteristics of hypodontia do not seem to follow a specific trend such that observed in sagittal skeletal relations $(11,16,17)$. Endo (2006) found that vertical dimension measurements (anterior and posterior facial height) had no significant differences between hypodontia group (anterior, posterior or both anterior and posterior dentition) and the control group (11). Similar prevalence of hypodontia among the hyper-divergent (11.2\%), normal (11.4\%) and hypodivergent $(10.3 \%)$ groups were reported (11). Nevertheless, severity of hypodontia may have a stronger association with vertical skeletal characteristics. Nodal et al (1994) observed significantly smaller mandibular plane angle, and gonial angle in a group of children with more than 12 teeth missing compared to that with 5-12 missing teeth (18). In addition, reduced vertical facial dimension and mandibular plane angle were observed in bilateral maxillary lateral agenesis cases by Woodworth et al (1985) (10). 
The 2 studies that investigated the association of third molar agenesis, and the vertical skeletal dimensions display conflicting results. Celikoglu and Kamak (2012) reported that agenesis of the third molar does not depend on vertical patterns of the skeletal malocclusions (6). There was similar prevalence rate of third molar agenesis among the hyper- divergent (24.5\%), normal (23.8\%), and hypodivergent $(19.2 \%)$ groups. In contrast, Sanches et al (2009) found that mandibular plane angles in patients with bilateral third molar agenesis either in maxilla (22.1응 or mandible $\left(22.8^{\circ}\right)$ were significantly lower than those with no agenesis (29.9ㅇ). In their study, patients with bilateral mandibular third molar agenesis had shorter lower face height (41.5 mm) compared to patients with no agenesis (46.6 mm) (14). Moreover, subjects with mandibular agenesis had wider articular angle than the control group which is related to increased vertical growth of the ramus, typical of brachyfacial patterns. In support of the findings published by Sanches et al, we demonstrated that individuals with short face and with deep bite had higher frequency of third molar agenesis both in the mandible and maxilla (14). We also found that those who had hypodivergant mandible had higher rate of third molar agenesis in the mandible, and those with an anteriorly rotated maxilla had higher rate of third molar agenesis in the maxilla.

The etiology of hypodontia remains unknown, but it appears to be an inherited characteristic (19). Rationale of the association between the small jaw size in sagittal plane, and decreased lower facial height with third molar agenesis is not clear. Some polygenic inheritance on formation of third molar germs suggested to be related to genes that control maxillary and/or mandibular dimensions8. De Coster et al (2009) stated that the list of genes involved in human non-syndromic hypodontia includes those encoding a signaling molecule (TGFA), and transcription factors (MSX1 and PAX9) that play critical roles during early craniofacial development (19). To our opinion, apart from genetic coding, higher frequency of third molar agenesis in retrognathic jaw morphology, may be as a result of influence of the presence of tooth germs in the bone on the growth and development of the jaws. The lack of vertical and anteroposterior growth in these subjects may be due to the reduction in the number of teeth. Conversely, the lack of space in both planes may result in physiological obstruction or disruption of the dental lamina or underlying mesenchyme. In support of this, the results of this study showed that, although not statistically significant, the mean arch length of agenesis group, both for the maxilla and mandible was smaller than that of the non-agenesis group. Kajii et al (2004) reported that the frequency of maxillary and mandibular third molar agenesis significantly increased with decreasing sagittal dimensions of the maxillary basal bone in Japanese orthodontic patients (20). We also showed that the jaw relations in sagittal plane were correlated with arch length in both jaws. In addition, the mean maxillary and mandibular effective lengths were shorter in the subjects with maxillary and mandibular third molar agenesis. Therefore, it may be proposed that agenesis of the third molars may also be due to space limitations of the dental arch.

Within the limitation of this study, it can be implied that apart from the generalized hypodontia, the absence or the presence of the third molars alone may be associated with the jaw morphology. Orthodontists should take into consideration that third molar agenesis is observed more frequently in the jaws with retrognathic dimensions on sagittal plane. In vertical plane, short face, deep bite, counterclockwise rotation of the mandible and clockwise rotation of the maxilla have higher percentage of third molar agenesis.

\section{References}

1. Tavajohi-Kermani H, Kapur R, Sciote J.(2002) "Tooth agenesis and craniofacial morphology in an orthodontic population." Am J Orthod Dentofacial Orthop. ;122:3947. 
2. Topkara A, Sari Z.(2011) "Prevalence and distribution of hypodontia in a Turkish orthodontic patient population: results from a large academic cohort." Eur J Paediatr Dent. 2011;12(2):123-127.

3. Aktan AM, Kara IM, Sener I, Bereket C, Ay S, Ciftci ME. (2010) "Radiographic study of tooth agenesis in the Turkish population." Oral Radiol.26:95-100.

4. Kazanci F, Celikoglu M, Miloglu O, Oktay H. (2010) "Third-molar agenesis among patients from the East Anatolian Region of Turkey." J Contemp Dent Pract. 11(4):E033-40.

5. Kajii T, Imai T, Kajii S, Iida J.(2001) "Presence of third molar germs in orthodontic patients in Japan. Am J Orthod Dentofacial Orthop." 119(3):245-250

6. Celikoglu M, Kamak H. (2012) "Patterns of third-molar agenesis in an orthodontic patient population with different skeletal malocclusions." Angle Orthod. 82(1):165-169.

7. Sandhu S, Kaur T.(2005) "Radiographic evaluation of the status of third molars in the Asian-Indian students." J Oral Maxillofac Surg. 63(5):640-645.

8. Celikoglu M, Miloglu 0, Kazanci F.(2010) "Frequency of agenesis, impaction, angulation, and related pathologic changes of third molar teeth in orthodontic patients." J Oral Maxillofac Surg. 68(5):990-995.

9. Laganà G, Lombardi CC, Franchi L, Cozza P.(2011) "Tooth agenesis: dentoskeletal characteristics in subjects with orthodontic treatment need." Eur J Paediatr Dent. 12(1):17-20.

10. Woodworth DA, Sinclair PM, Alexander RG.(1985) "Bilateral congenital absence of maxillary lateral incisors: a craniofacial and dental cast analysis." Am J Orthod. 87(4):280-293.
11. Endo T, Ozoe R, Yoshino S, Shimooka S.(2006) "Hypodontia patterns and variations in craniofacial morphology in Japanese orthodontic patients." Angle Orthod. 76(6):996-1003.

12. Øgaard B, Krogstad O.(1995) "Craniofacial structure and soft tissue profile in patients with severe hypodontia." Am J Orthod Dentofacial Orthop. 108:472477.

13. Yuksel S, Ucem T.(1997) "The effect of tooth agenesis on dentofacial structures." Eur J Orthod. 19:133-143.

14. Sánchez MJ, Vicente A, Bravo LA. (2009) "Third molar agenesis and craniofacial morphology." Angle Orthod.79(3):473-478.

15. Mitchell L. (2013) Introduction to Orthodontics. $4^{\text {th }}$ edition. Oxford: Oxford University Press;

16. Celikoglu M, Kazanci F, Miloglu O, Oztek O, Kamak H, Ceylan I. (2010)

17. "Frequency and characteristics of tooth agenesis among an orthodontic patient population." Med Oral Patol Oral Cir Bucal 15 (5):e797-801.

18. Chung CJ, Han JH, Kim KH.(2008) "The pattern and prevalence of hypodontia in Koreans." Oral Dis. 14(7):620-625.

19. Nodal M, Kjaer I, Solow B.(1994) "Craniofacial morphology in patients with multiple congenitally missing permanent teeth." Eur J Orthod. 16:104-109.

20. De Coster PJ, Marks LA, Martens LC, Huysseune A. (2009) "Dental agenesis: genetic and clinical perspectives." J Oral Pathol Med. 38(1):1-17.

21. Kajii T, Sato Y, Kajii S, Sugawara Y, Lida J. (2004) "Agenesis of third molar germs depends on sagittal maxillary jaw dimension in orthodontic patient in Japan." Angle Orthod. 74: 337-342. 